\title{
PESQUISA ESCOLAR: PERCURSO DE AÇÃO RUMO AO CONHECIMENTO
}

\author{
INVESTIGACIÓN ESCOLAR: CURSO DE ACCIÓN HACIA EL \\ CONOCIMIENTO
}

\author{
Ana Cristina de Albuquerque - albuanati@uel.br \\ Doutora em Ciência da Informação pela Universidade Estadual \\ Paulista (UNESP/Marília). Professora do Programa de Pós-Graduação em \\ Ciência da Informação da Universidade Estadual de Londrina (UEL). \\ Claudineia Aparecida Bertin Borges - abb_neia@hotmail.com \\ Especialista em Gestão de Biblioteca Escolar pela \\ Universidade Estadual de Londrina (UEL).
}

\section{RESUMO}

Introdução: O presente trabalho busca apresentar a importância da biblioteca escolar, aprofundando-se as discussões já iniciadas sobre o tema. Ao mesmo tempo exibe a relevância da atuação do bibliotecário na busca da geração do conhecimento por meio da prática da pesquisa, da reflexão e da discussão.

Objetivo: Analisar por meio da literatura da área de ciência da informação, como o bibliotecário pode contribuir e incentivar a pesquisa na escola.

Metodologia: Pesquisa bibliográfica, com levantamento de literatura científica relacionada à temática sobre a pesquisa escolar e ao trabalho do bibliotecário. Levantamento de relatos de pesquisa e relatos de experiência sobre ações desenvolvidas com o objetivo de promover 0 estímulo à pesquisa.

Resultados: Nos vários relatos de experiência e de pesquisa analisados durante a pesquisa percebeu-se que o trabalho só surtiu efeito ou foi conduzido de forma satisfatória quando nela estavam envolvidos vários agentes: professor, aluno, bibliotecário, etc.

Conclusões: Quando se aborda as relações existentes entre a pesquisa, o bibliotecário e o conhecimento, são reveladas inúmeras implicações, as quais, trazidas pelos relatos compilados, devem ser consideradas como elementos basilares para a compreensão da importância de se implementar, no âmbito das bibliotecas escolares, ações concretas de estímulo à competência informacional. 
Palavras-chave: Biblioteca. Pesquisa. Ensino Fundamental. Bibliotecário.

\section{INTRODUÇÃO}

O presente artigo tem como base alguns resultados da monografia, com o mesmo título, apresentada à Especialização em Gestão de bibliotecas Escolares no ano de 2012. Tem como objetivo investigar como o bibliotecário pode contribuir para incentivar a prática da pesquisa na escola, transformando a biblioteca em espaço de conhecimento.

É indiscutível que o ensino não se dá exclusivamente em sala de aula, e sendo a Biblioteca Escolar um órgão de apoio no ensino, o profissional que nela atua pode e deve ter um papel de fundamental importância na condução e no direcionamento do aluno ao empreendimento de pesquisa. O bibliotecário pode atuar com mais propriedade junto aos alunos promovendo debates, confrontando ideias, fazendo acontecer um processo de aprendizagem baseado em questionamentos e acima de tudo buscar o envolvimento efetivo do aluno no processo de construção do conhecimento.

Num trabalho de pesquisa, ocorre um processo denominado de geração do conhecimento (DEMO, 1983). Assim sendo, não basta ao bibliotecário apenas fornecer os recursos informacionais que a biblioteca dispõe. Acima de tudo, este profissional deve atuar como facilitador e capacitador num processo de construção da aprendizagem, com vistas à transformação dessa realidade.

A importância da biblioteca escolar é confirmada por Campello (2009, p. 19), quando a autora pontifica que:

Democratizar o acesso à informação, capacitar as pessoas para o uso crítico da informação, proporcionar condições que permitam a reflexão, a crítica e a construção de ideias por meio da leitura são ações constantemente recomendadas para o bibliotecário e, no bojo dessas ações a biblioteca escolar é vista como espaço privilegiado para seu desenvolvimento.

No mundo contemporâneo, uma grande parcela da população tem acesso a uma gama de informações. No entanto, faz-se necessário que, desde os níveis básicos da escolarização, os alunos desenvolvam habilidades para identificar a relevância dos conteúdos veiculados pelos meios de comunicação e demais canais informacionais. 
Cabe ao bibliotecário, em um trabalho conjunto com o professor, desenvolver atividades por meio das quais o aluno possa adquirir tais habilidades para construir sentido por si mesmo. Assim, este profissional desempenha um papel central na criação desse tipo de ambiente de aprendizagem, transformando a biblioteca escolar em espaço de questionamentos que fornece acesso a recursos para aprendizagem em todas as áreas do conhecimento (KUHLTHAU, 1999).

Tendo em vista os pressupostos apresentados, optou-se por realizar a análise de relatos de pesquisa e relatos de experiência publicados em periódicos científicos dos anos de 2003 a 2011, que abordem ações desenvolvidas por bibliotecários nas escolas no intuito de incentivar a pesquisa neste espaço de construção do conhecimento.

\section{A PESQUISA COMO SUBSTRATO DO PROCESSO EDUCATIVO}

Ao se refletir sobre a educação brasileira em seus primórdios, retoma-se a figura do mestre como detentor de toda a sabedoria e seus pupilos como depositórios de informações nem sempre vinculadas a um contexto de aprendizagem coerente com as necessidades dos aprendizes.

Naquela situação, tudo estaria perfeito enquanto os alunos reproduzissem exatamente o que o Mestre mandara. O tempo foi passando e muitos avanços ocorreram na área educacional, embora se possa constatar, com perplexidade, que em muitas escolas o cerne da questão continuou inalterado. Surgem, então, algumas indagações: $O$ aluno que recebe aulas expositivas realmente adquire conhecimento? A escola está cumprindo sua função social de oferecer aos alunos condições para que este construa 0 aprendizado?

Para estas questões, buscam-se respostas nos posicionamentos de autores que defendem a intencionalidade da pesquisa como substrato para a consolidação de um processo educativo de qualidade.

$\mathrm{Na}$ busca pelo desenvolvimento integral dos atores sociais que compõem o universo educativo, muitos pesquisadores procuram atualmente pela melhor forma de se ensinar. É sabido que nos moldes convencionais o ensino nem sempre garante o aprendizado. Várias pesquisas deixam entrever a existência de lacunas deixadas pelo processo tradicional de ensino. 
Nesta linha de pensamento, Kuhlthau (2002, p. 9-10) reafirma a importância de se garantir a todos os alunos, sem distinção, os saberes elaborados socialmente, como instrumentos para o desenvolvimento da socialização e, consequentemente, da cidadania democrática.

Os saberes elaborados socialmente estão registrados em materiais diversos, que vão desde os tradicionais textos impressos, passando pelos recursos audiovisuais, até as informações virtualmente dispostas. [...] Para se preparar para as atuais complexas condições de trabalho o estudante tem que desenvolver a capacidade de aprender continuamente: precisa ter autonomia na sua relação com o conhecimento, isto é, deve conhecer suas próprias necessidades de informação e saber como obtê-la e utilizá-la para atender seus propósitos.

A autora enfatiza também que os alunos vão à escola com uma certa bagagem formada por conhecimentos que de maneira alguma devem ser desperdiçados ou desprezados e que justamente estes conhecimentos devem ter um aporte na escola para que possam ser desenvolvidos e ampliados, visto que a escola é o lugar ideal para este feito pois deve apresentar recursos suficientes para que esses alunos possam "refinar" e expandir as habilidades que carregam e suas possíveis relações (KUHLTHAU, 2002).

É justamente neste propósito de aprender continuamente que a pesquisa encontra seu papel não apenas na escola, mas nas situações cotidianas que exigem do homem uma constante adaptação aos desafios que se interpõem entre ele e o conhecimento.

A pesquisa é um dos motes principais para a aquisição do conhecimento, e, segundo Almeida Júnior (2006, p. 101) "[...] deve ser encarada como um instrumento pedagógico, imprescindível na formação do aluno e o espaço onde ela, pesquisa, ocorre, como fazendo parte do ambiente necessário para a formação do cidadão."

Demo (2011, p. 7) postula que "A própria vida como tal é um espaço naturalmente educativo, à medida que induz à aprendizagem constante, burila a têmpera das pessoas, forma no sofrimento e na experiência acumulada."

No que diz respeito à pesquisa, Demo (1983, p. 22) afirma que:

A atividade básica da pesquisa é a ciência, esta afirmação pode estranhar, porque temos a ideia de que ciência se concentra na atividade de transmissão de conhecimento (docência) e de absorvê-la (discência). Na verdade, tal atividade é subsequente. Antes existe 0 fenômeno fundamental da geração do conhecimento. 
Não se trata, contudo, de colocar a pesquisa feita no Ensino Fundamental no mesmo nível da pesquisa científica e sim desenvolver estratégias desde os níveis iniciais para que, a partir disso, as crianças desenvolvam autonomia na busca de informação e formulação de ideias.

Como afirma Almeida Júnior (2006, p. 103): "Só há solução para o problema da pesquisa escolar, em meu entender, se o modelo educacional se transformar, deixando o foco da reprodução para se voltar para a reflexão, para o debate, para a discussão."

Neste estudo, a busca pela geração do conhecimento é uma importante finalidade do trabalho do bibliotecário, por meio da pesquisa, do levantamento de hipóteses, do estímulo à reflexão e à discussão.

Sabe-se ainda que inúmeros são os espaços e agentes que podem ser considerados educativos, como as rodas de amigos e o ambiente de trabalho, mas este aprendizado se dá por expedientes distintos da pesquisa, em que somente se configura em seu sentido pleno na escola (DEMO, 2011).

Novamente reitera-se a importância do papel da pesquisa também para o professor, uma vez que dele são exigidos saberes que extrapolam a mera transmissão de informação e requerem um contínuo reposicionamento sobre aquilo que aprendeu e aquilo que ensina - para atingir aquilo que pretende que o aluno possa construir.

Assim, convém mencionar os pressupostos elencados por Demo (2011), sobretudo quando se especifica a escola como lócus da educação pela pesquisa, com vistas a fazer dela atitude cotidiana no professor e no aluno, e a tarefa da educação como processo de formação da competência histórica humana.

No que diz respeito à necessidade de se utilizar a pesquisa como componente central que permite a abordagem interdisciplinar no âmbito escolar, entende-se que a interação entre a teoria e a prática mediante o estabelecimento de relações entre os conteúdos do ensino e a realidade social escolar pode ser adotada como meio de imprimir maior sentido às situações educativas.

Assim, quando se propõe uma pesquisa escolar, abrem-se novos horizontes que podem ser desvelados tendo em vista a amplitude das informações presentes no contexto informacional contemporâneo, demarcado pela elevada incidência de informações as quais nem sempre são assimiladas em sua totalidade pelos indivíduos.

Nestas condições, o aluno, ao realizar uma pesquisa, insere-se em um universo ilimitado de informações que extrapolam as disciplinas escolares e permitem a superação 
do senso comum e a manutenção de atitudes de crítica e reconstrução dos saberes trazidos pela prática da pesquisa.

Da mesma forma, a pesquisa contribui de forma incontestável para aprimorar este processo de construção e reconstrução, mas para que isso realmente ocorra deve ser bem conduzida.

Partindo do postulado de que "[...] a criança é, por vocação, um pesquisador pertinaz, compulsivo." (DEMO, 2011, p. 14), percebe-se que a escola, em muitas situações, tolhe esta qualidade infantil, sobretudo quando tenta impor normas disciplinares, ou a imitação do comportamento adulto.

Entende-se que é vital instigar o questionamento reconstrutivo, evocado por Demo (2011, p. 35):

O questionamento reconstrutivo começa, pois, com o saber procurar e questionar (pesquisa). O aluno será motivado a tomar iniciativa, apreciar leitura e biblioteca, buscar dados e encontrar fontes, manear conhecimento disponível e mesmo o senso comum.

Neste ponto, retoma-se a competência profissional como atributo imprescindível para trabalhar a pesquisa como substrato da formação de um ambiente didático cotidiano.

Da mesma forma, quando a pesquisa se revela como uma atitude cotidiana, envolve outro fator essencial para a obtenção de resultados mais expressivos da educação escolar, que se volta para o desenvolvimento da criticidade tão necessária à potencialidade de intervenção na realidade.

Reitera-se, portanto, o aspecto singelo da pesquisa cotidiana, que nem sempre precisa estar vinculada a um projeto especial, bastando o sujeito que deseja aprender e as condições para satisfazer esta necessidade, inerente à criança como Demo a entende, pesquisadora contumaz.

Trata-se, portanto, de prover meios para que a pesquisa como atitude cotidiana, a partir da ação intencional do professor, seja reflexo desta sua forma de trabalhar em sala de aula e se apresente para o aluno como um ponto de partida e de chegada do processo de construção de sua aprendizagem. Assim, o professor toma o aluno como parceiro em seus percursos de aprendizagem.

Principalmente na educação básica, a observação do cenário escolar demonstra que o desafio de educar pela pesquisa é tomado como um obstáculo intransponível por muitos profissionais que atuam neste nível de ensino. 
No entanto, ao buscar um trabalho voltado para a pesquisa ainda nas séries iniciais, percebe-se que os horizontes de possibilidade mostram-se muito mais amplos, posto que o desenvolvimento da habilidade de pesquisa integra o processo contínuo de aprendizagem.

\section{ANÁLISE E DISCUSSÃO BASEADA NOS ARTIGOS DE PERIÓdICOS CIENTÍFICOS}

O trabalho foi desenvolvido a partir de pesquisa bibliográfica, com levantamento de literatura científica relacionada com a temática da pesquisa escolar na área da Ciência da Informação.

Foi realizado, no período entre agosto e novembro de 2012, minucioso levantamento em livros, artigos, trabalhos acadêmicos nacionais e em sites da internet, tendo como temas centrais biblioteca escolar e o trabalho do bibliotecário na condução do processo de pesquisa.

A pesquisa permitiu analisar periódicos científicos da área no que diz respeito às ações desenvolvidas pelos bibliotecários nas escolas, relacionadas à pesquisa escolar. Após este levantamento, foram descritos e sistematizados os resultados.

A escolha dos relatos que integram a presente análise amparou-se nos critérios de seleção de revistas com indicação Qualis A1, B1, A2 e B2; buscando-se analisar relatos de experiências e relatos de pesquisa, publicados em português, no período de 2003 a 2011. Os relatos selecionados são apresentados no quadro a seguir. 
Quadro 1 - Relatos de experiência e de pesquisa de periódicos A1, B1, A2 e B2 nas áreas de Biblioteconomia e Ciência da Informação

\begin{tabular}{|c|c|c|c|}
\hline & ARTIGO & REVISTA & AUTOR \\
\hline 1 & $\begin{array}{l}\text { As possibilidades pedagógicas no } \\
\text { ensino de metodologia da pesquisa } \\
\text { científica em ciência da informação e os } \\
\text { objetos deste campo científico: } \\
\text { aproximações durkheinianas }\end{array}$ & $\begin{array}{l}\text { Enc. Bibli: R. Eletr. } \\
\text { Bibliotecon. Ci. Inf., } \\
\text { Florianópolis, n. } 16,2^{\circ} \\
\text { sem. } 2003\end{array}$ & $\begin{array}{l}\text { Francisco das } \\
\text { Chagas de } \\
\text { Souza }\end{array}$ \\
\hline 2 & $\begin{array}{l}\text { A Utilização das Tecnologias de } \\
\text { Informação e de Comunicação na } \\
\text { Pesquisa Escolar: um estudo de caso } \\
\text { com os PNEEs com limitação visual }\end{array}$ & $\begin{array}{l}\text { Em Questão, Porto } \\
\text { Alegre, v. 10, n. 1, p. 185- } \\
\text { 199, jan./jun. } 2004\end{array}$ & $\begin{array}{l}\text { Eliane L. S. } \\
\text { Moro; } \\
\text { Lizandra } \\
\text { Brasil Estabel }\end{array}$ \\
\hline 3 & $\begin{array}{l}\text { "Quissamã somos nós!":construção } \\
\text { participativa de hipertexto }\end{array}$ & $\begin{array}{l}\text { Ci. Inf., Brasília, v. 33, n. } \\
\text { 1, p. 155-168, jan./abril } \\
2004\end{array}$ & $\begin{array}{l}\text { Carmelita E. } \\
\text { Santo } \\
\text { Isa Maria } \\
\text { Freire }\end{array}$ \\
\hline 4 & $\begin{array}{l}\text { Biblioteca do Colégio Estadual Manoel } \\
\text { Vilaverde: um espaço além das quatro } \\
\text { paredes }\end{array}$ & $\begin{array}{l}\text { Revista Digital de } \\
\text { Biblioteconomia e Ciência } \\
\text { da Informação, Campinas, } \\
\text { v. 3, n. 1, p. 152-164, } \\
\text { jul./dez. } 2005\end{array}$ & $\begin{array}{l}\text { Maria } \\
\text { Aparecida } \\
\text { Rodrigues de } \\
\text { Souza }\end{array}$ \\
\hline 5 & $\begin{array}{l}\text { Information literacy: uma análise nas } \\
\text { bibliotecas escolares da rede privada } \\
\text { em Natal / RN }\end{array}$ & $\begin{array}{l}\text { Revista Digital de } \\
\text { Biblioteconomia e Ciência } \\
\text { da Informação, Campinas, } \\
\text { v. } 4 \text {, n. } 2 \text {, p. } 110-133 \text {, } \\
\text { jan./jun. } 2007\end{array}$ & $\begin{array}{l}\text { Clediane } \\
\text { Araújo } \\
\text { Guedes; } \\
\text { Gabriela B. } \\
\text { Farias }\end{array}$ \\
\hline 6 & $\begin{array}{l}\text { Alfabetização digital: proposição de } \\
\text { parâmetros metodológicos em } \\
\text { competência informacional }\end{array}$ & $\begin{array}{l}\text { Inf. \& Soc. Est., João } \\
\text { Pessoa, v.19, n.2, p. } 81- \\
\text { 98, maio/ago. } 2009\end{array}$ & $\begin{array}{l}\text { João de } \\
\text { Pontes Junior; } \\
\text { Maria F. G. M. } \\
\text { Tálamo }\end{array}$ \\
\hline 7 & $\begin{array}{l}\text { O bibliotecário escolar incentivando a } \\
\text { leitura através da webquest }\end{array}$ & $\begin{array}{l}\text { Perspectivas em Ciências } \\
\text { da Informação, Belo } \\
\text { Horizonte, v. 14, n.1, p. } \\
\text { 37-54, jan/abr } 2009\end{array}$ & $\begin{array}{l}\text { Wilse A. da } \\
\text { Costa; Mariza } \\
\text { I. da Silva } \\
\text { Pinheiro; } \\
\text { Maria N.da } \\
\text { Silva Costa. }\end{array}$ \\
\hline 8 & Educação e bibliotecas digitais & $\begin{array}{l}\text { Revista Digital de } \\
\text { Biblioteconomia e Ciência } \\
\text { da Informação, Campinas, } \\
\text { v.8, n. 1, p.103-116, } \\
\text { jul./dez. } 2010\end{array}$ & $\begin{array}{l}\text { Cassia } \\
\text { Furtado }\end{array}$ \\
\hline 9 & $\begin{array}{l}\text { O bibliotecário na escola de educação } \\
\text { básica: depoimentos de profissionais de } \\
\text { Santa Catarina }\end{array}$ & $\begin{array}{l}\text { Inf. \& Soc. Est., João } \\
\text { Pessoa, v.21, n.2, p. 121- } \\
\text { 131, maio/ago. } 2011\end{array}$ & $\begin{array}{l}\text { Eliane } \\
\text { F.Garcez } \\
\text { Miriam } \\
\text { V.Cunha }\end{array}$ \\
\hline
\end{tabular}




\begin{tabular}{|l|l|l|l|}
\hline 10 & $\begin{array}{l}\text { Parâmetros para bibliotecas escolares } \\
\text { brasileiras: fundamentos de sua } \\
\text { elaboração I }\end{array}$ & $\begin{array}{l}\text { Inf. \& Soc. Est., João } \\
\text { Pessoa, v.21, n.2, p. 105- } \\
120, \text { maio/ago. 2011 }\end{array}$ & $\begin{array}{l}\text { Bernadete S. } \\
\text { Campello et } \\
\text { al. }\end{array}$ \\
\hline 11 & $\begin{array}{l}\text { Revista Digital de } \\
\text { As transformações da escrita e seus } \\
\text { Biblioteconomia e Ciência } \\
\text { da Informação, Campinas, do passado ao presente } \\
\text { v8, n. 2, p. 199-208, } \\
\text { jan./jun. 2011. }\end{array}$ & $\begin{array}{l}\text { Raquel } \\
\text { Pacheco }\end{array}$ \\
\hline 12 & $\begin{array}{l}\text { Especialização em bibliotecas escolares } \\
\text { e acessibilidade: discutindo a gestão da } \\
\text { biblioteca na modalidade EAD }\end{array}$ & $\begin{array}{l}\text { Inf. Inf., Londrina, v. 16, } \\
\text { n.1, p. 102-123, jan./jun. } \\
2011\end{array}$ & $\begin{array}{l}\text { Ariel Behr et } \\
\text { al. }\end{array}$ \\
\hline
\end{tabular}

Fonte: Dados extraídos da pesquisa.

A partir dos relatos selecionados, torna-se possível tecer algumas considerações sobre os resultados obtidos pelos autores nas mais variadas experiências e sua pertinência com o objeto deste estudo. Estes foram agrupados de acordo com as temáticas debatidas.

Em primeiro plano, deve-se atentar para a importância da inserção das tecnologias da informação e da comunicação quando se pretende viabilizar a pesquisa como substrato para a construção do conhecimento no âmbito escola e da sociedade deste início de século.

$\mathrm{Na}$ direção pretendida, os relatos 3 e 7 mostram-se importantes para comprovar a exequibilidade de propostas que contemplem as ferramentas tecnológicas como forma de otimizar o trabalho de pesquisa na biblioteca escolar.

No Relato 3, Espírito Santo e Freire (2004) reforçam a necessidade de abordar o trabalho na biblioteca escolar sob a perspectiva da responsabilidade social da ciência da informação, uma vez que as ações neste espaço de aprendizagem derivam de uma ação informacional com vistas a produzir, organizar e socializar o conhecimento.

As autoras reportam-se à experiência com o hipertexto, concebido como ferramenta para resgatar a identidade cultural da comunidade de Quissamã-RJ, a partir da compilação de elementos que representam a cultura local, com posterior disponibilização na Internet, considerado pelas autoras como o espaço potencial de socialização da informação (ESPÍRITO SANTO; FREIRE, 2004).

Reforça-se, neste sentido, que ao longo do processo de produção da informação, ocorre também sua socialização, visando atingir um contexto comunitário em que 
produtores e usuários de informação participaram de forma ativa e igualitária na sua realização (ESPÍRITO SANTO; FREIRE, 2004).

Por sua vez, Pinheiro et al. (2009), no Relato 7, descrevem sua experiência com a elaboração de uma webquest junto a alunos de quinta série, a partir da temática Magia da leitura, que teve como objetivo propiciar condições de os alunos adquirirem conhecimento por meio da pesquisa pela Internet e por outros meios informacionais.

As autoras salientam que à escola cabe fornecer os meios necessários à busca do conhecimento para a construção dos saberes, mas advertem que não basta equipar as escolas, é vital capacitar professores e funcionários para dar o suporte necessário às ações de pesquisa escolar. Assim, a informática no âmbito escolar deve ser concebida como um recurso para a otimização das atividades curriculares. Da mesma forma, tratase de um apoio pedagógico, e não uma metodologia de ensino (PINHEIRO et al., 2009).

As autoras ressaltam ainda a importância do bibliotecário como profissional que possui a possibilidade de fomentar a leitura por meio da Internet, podendo esta ser concebida como uma ferramenta envolvente, motivadora, diversificada, atualizada, questionadora e geradora de opinião (PINHEIRO et al., 2009).

Os dois relatos analisados corroboram a ideia de que a pesquisa configura-se como uma importante atividade no âmbito escolar e que pressupõe, conforme afirma Demo (2011) a necessidade de formulação de questionamentos reconstrutivos, sem o qual a construção do conhecimento não se concretiza.

Por isso, ratifica-se o pensamento de Demo (2011), quando o autor considera a pesquisa como ação cotidiana a ser desenvolvida não apenas no contexto social em que se insere o aluno, mas também - e principalmente - o professor e, por extensão, o bibliotecário, como co-responsável pelo processo ensino e aprendizagem.

Outro bloco de análise dos relatos selecionados refere-se a experiências de leitura, constantes nos relatos 1,4 e 11, embora esta temática perpasse todos os relatos, na medida em que o substrato de quaisquer atividades que envolvam a pesquisa é, de forma inequívoca, a leitura.

No Relato 1, Souza (2003) desenvolve uma discussão acerca do processo educacional e de investigação, com o objetivo de aclarar as dificuldades manifestadas pelos estudantes em relação aos tipos de pesquisa a ser realizados em determinada situação de aprendizagem.

Reforça-se, ao longo do relato, a importância de se pautar as atividades de 
pesquisa no ensino superior no fortalecimento da educação fundamental e média, a qual se situa na dependência de infraestrutura de leitura de diversas mídias que possam ser disponibilizadas não somente nas escolas, mas nos demais espaços educativos compreendidos pela família e sociedade em um contexto ampliado (SOUZA, 2003).

Ainda no que diz respeito a experiências educativas com vistas a promover 0 incentivo à leitura, no Relato 11, Pacheco (2011) apresenta os resultados de uma oficina de leitura com alunos da Educação Infantil, tendo como tema gerador o surgimento da escrita.

Deste modo, a autora relata, após um longo período de pesquisa em diferentes meios, bem como de manipulação de diferentes objetos, os alunos puderam assistir a um filme produzido com o material encontrado e passado.

Deste modo, ficou comprovado que a biblioteca escolar é o espaço de trabalho em que o bibliotecário escolar deve atuar, visando à interação de alunos e de professores, além de facilitar o acesso à informação para o processo ensino-aprendizagem. Nesta perspectiva, entende-se que a pesquisa é estimulada na escola quando a criança tem contato com a biblioteca desde pequena (PACHECO, 2011).

Em outro relato, Souza (2005) avalia a prestação de serviços e atividades de leitura desenvolvidas em uma biblioteca escolar, sobretudo na implantação de projetos de leitura e de melhoria dos recursos pedagógicos da instituição.

Desta forma, ao longo do Relato 4, é possível perceber que o bibliotecário assume papel de especial importância, como mediador do usuário com a leitura e a pesquisa.

As experiências de leitura contidas nos relatos 1 , 4 e 11 reforçam a possibilidade de execução de ações concretas de pesquisa a partir do envolvimento dos diferentes profissionais da instituição escolar, em especial o bibliotecário, na consolidação de suportes concretos para a realização de atividades cujo principal instrumento de ação seja a pesquisa.

Dada esta importância atribuída à pesquisa, ressalta-se, neste ponto da discussão, os resultados abstraídos do Relato 2, de Moro e Estabel (2004), em que as autoras refletem sobre os resultados de ação pedagógica desenvolvida junto a sujeitos com limitação visual, a partir da inserção das TIC's no processo pedagógico.

As autoras consideram a pesquisa escolar como um processo racional e sistemático, em que se utiliza um método de pensamento reflexivo que requer um 
tratamento científico e tem como objetivo buscar respostas aos problemas sugeridos (MORO; ESTABEL, 2004).

Aos professores cabe orientar e subsidiar todas as etapas para a realização da pesquisa escolar, seguindo um roteiro pré-definido que contemple o tema a ser pesquisado, os objetivos que se pretende alcançar com a atividade, as formas de busca, de elaboração e de apresentação do trabalho, bem como as fontes, locais ou referências (MORO; ESTABEL, 2004).

Pela aplicação de instrumento de coleta de dados aos alunos, Moro e Estabel (2004) obtiveram informações que comprovaram que a Internet tem influência na pesquisa escolar, mas é importante que esta etapa seja dotada dos requisitos necessários à formação da competência informacional, conforme se observa quando se retomam as ideias de Campello (2009), quando a autora menciona o acesso à informação de forma eficiente, a avaliação dessa informação criticamente e seu efetivo uso com competência e criatividade como requisitos deste tipo de competência a ser perseguido pela escola e pelo bibliotecário de forma mais particular.

Deste modo, as discussões trazidas à tona pela experiência constante no relato 2 permitiram o engendramento de sugestões para que a pesquisa seja realizada com qualidade pelos alunos. Tais sugestões envolvem a manutenção da

Biblioteca atualizada com fontes de informação em diferentes suportes, a solicitação de temas que despertem o interesse do aluno; a qualificação do professor para orientação da pesquisa escolar, dentre outras.

Novamente deve-se reforçar a ideia da biblioteca como espaço de aprendizagem, e a figura do bibliotecário como agente das mudanças que se desejam ver efetivadas na construção de sujeitos pesquisadores, nos moldes previstos por Khulthau (2002), quando aponta a escola como o espaço privilegiado em que se pode ampliar e aprofundar o contato com a variedade de recursos atualmente disponíveis, gerando conhecimentos e estimulando a construção de novos saberes.

Assim, no bloco subsequente de análise, busca-se considerar os artigos que tratam especificamente das bibliotecas escolares. Nesta dimensão, pode-se perceber que os relatos 10 e 12 convergem para esta temática.

Campello et al. (2011), no Relato 10, abordam a importância da elaboração dos padrões para bibliotecas escolares brasileiras e apresentam os princípios, referenciais teóricos e critérios que os embasaram. Os autores pontuam que tais padrões visam à 
melhoria do processo educativo, na medida em que boas bibliotecas escolares constituem elementos que influenciam positivamente o ensino básico.

O processo de elaboração dos padrões foi fundamentado na noção da biblioteca como espaço de aprendizagem. Desta forma, os autores contemplam tais parâmetros como instrumentos inovadores no sentido de criar e aperfeiçoar bibliotecas escolares a partir desta noção (CAMPELLO et al, 2011).

Trata-se, assim, de um ponto de partida para ações que levem à melhoria da qualidade das bibliotecas escolares brasileiras e, ao mesmo tempo, uma oportunidade para que os bibliotecários tracem objetivos comuns que darão maior visibilidade à profissão.

Por sua vez, a pesquisa realizada por Behr et al. (2011), constante no Relato 12, tendo sido concretizada com profissionais de bibliotecas escolares de três diferentes estados brasileiros, concluiu que a biblioteca escolar, como outro serviço qualquer, deve ser gerenciada de maneira a atender seus objetivos, e melhorar sempre que possível a qualidade dos serviços prestados. Nesta forma de pensar, o bibliotecário deixa de ser visto apenas como um gerente de informações e passa a atuar como gerente de um ambiente que exige constantes inovações práticas e materiais.

Outro importante ponto para discussão trazido à tona por Furtado (2010) no Relato 8, diz respeito ao distanciamento entre a proposta de implantação de bibliotecas digitais e a realidade de muitas bibliotecas escolares, sucateadas e mantidas à margem das reais necessidades advindas das demandas da sociedade da informação.

Deste modo, a autora pondera que a quantidade, diversidade e possibilidade de reprodução sem limites da informação trouxe grande impacto às bibliotecas, que ainda continua a ser relegada a um papel de menor importância no âmbito escolar.

A biblioteca digital representa uma evolução do resultado da utilização do computador e da Internet nos serviços da biblioteca e pode ser conceituada como uma coleção organizada de informação, em formato digital, acessível pela rede mundial de computadores. Traz como benefícios a superação dos os limites físicos, geográficos e temporais (FURTADO, 2010).

Salienta-se assim a possibilidade de ligação virtual entre todas as bibliotecas, elevando a biblioteca escolar à condição de espaço central de informação da escola. Furtado (2010) reforça que, embora a biblioteca escolar tenha sofrido muitas alterações 
em termos conceituais, assumindo a posição de centro ativo de aprendizagem, seu espaço de atuação ainda se mostra limitado.

Novamente deve se reforçar o papel preponderante do bibliotecário na transposição dos obstáculos referidos por Furtado (2010). Assim, deve-se destacar, conforme a posição assumida por Bicheri (2008) as tarefas essenciais do bibliotecário, sobretudo no que se refere às ações de conhecer, atender, orientar e cativar seus usuários, auxiliando-os em sua construção de conhecimento, para que sejam, eles mesmos, produtores de novas informações.

Diante das atribuições requeridas pelo bibliotecário, sobretudo no âmbito escolar, cabe tecer considerações acerca dos resultados evidenciados nos relatos 5, 6 e 9, que tratam especificamente da atuação deste profissional.

No Relato 5, Guedes e Farias (2007) avaliam os dados resultantes da aplicação de questionários aplicados em bibliotecas escolares, com vistas a analisar a competência em informação neste ambiente. As autoras reportam-se à necessidade de integração entre escola-biblioteca, e a inserção do bibliotecário na comunidade educacional para criação de programas educacionais voltados para a competência em informação.

É reforçado, ao longo da pesquisa constante do relato 5, o papel da biblioteca escolar como espaço de competência em informação, e a atuação do bibliotecário como agente educacional responsável pela mediação de aprendizado.

Um dos enfoques presentes no relato de Guedes e Farias (2007) diz respeito à information literacy, ou competência em informação, quando se comprova a importância do desenvolvimento dessa competência na sociedade da informação, bem como no âmbito da biblioteca escolar, provocando mudanças e atitudes dos profissionais bibliotecários, mostrando-lhes a necessidade e, sobretudo, as possibilidades de ações proativas voltadas para a ampliação da competência em informação dos alunos. Nesta via de pensamento, não somente cabe à biblioteca escolar estimular a busca pela informação, mas também, desenvolver competências para que os seus usuários possam saber fazer uso crítico da mesma para tomar decisões e resolver problemas.

Pontes Júnior et al. (2009), no Relato 6, tomam como objeto de estudo a metodologia de capacitação de programa de Alfabetização Digital do Biblioredes (Chile), que propõe que os seus participantes sejam inicialmente alfabetizados no acesso a computadores, softwares e Internet. 
Assim, espera-se do indivíduo com competência informacional é que ele pense de forma individual e crítica, valendo-se da recuperação e uso da informação de forma inesgotável. Deste modo, a alfabetização digital estará completa quando o sujeito não só reconhece que a informação precisa e completa é a base para a tomada de decisão inteligente, mas também quando formula questões baseadas em necessidades informacionais; identifica possíveis fontes de informação; desenvolve estratégias de busca bem sucedidas; avalia, organiza e integra a informação para sua aplicação prática; na resolução de problemas e no pensamento crítico (PONTES JÚNIOR et al. 2009).

Os resultados da Alfabetização Digital, ainda segundo os mesmos autores, devem proporcionar um aumento da autoestima o desenvolvimento do indivíduo, em decorrência da diminuição de seu estado de exclusão digital. Da mesma forma, são consolidadas as competências necessárias para realizar uma busca e fazer um uso eficiente da informação, além do compartilhamento de conhecimentos adquiridos e vivenciados, conforme se pode comprovar pelos resultados detalhados nos relatos 3 e 7 .

Da mesma forma, a alfabetização digital permite aplicar os conceitos e aprendizados sobre o processo de busca e uso da informação em seu meio acadêmico, profissional e pessoal.

Referindo-se especialmente aos bibliotecários, os autores pontuam que este profissional deve buscar continuamente a atualização diante das tecnologias, com vistas a promover a gestão da informação com foco no usuário.

No Relato 9, Garcez e Cunha (2011) abordam de maneira específica a atuação do bibliotecário no ambiente escolar. Sustentam que a informação e conhecimento são elementos imprescindíveis no processo de tomada de decisões. Por este motivo, é importante viabilizar o acesso e o uso da informação de forma competente. A escola, nesta dimensão, representa o ambiente e a pesquisa escolar assume a posição de um dos caminhos possíveis para desenvolverem essa habilidade.

É reforçada a ideia de que a escola deve ter reforçado seu papel histórico de local de socialização e democratização da informação. Neste cenário, a presença do bibliotecário mostra-se essencial para melhorar a interlocução entre professores, diretores e equipe pedagógica com relação aos problemas relacionados à pesquisa escolar.

A partir das observações trazidas pelos autores dos relatos e diante das ideias revisitadas de alguns autores, entende-se que a tarefa do bibliotecário não deve ser reduzida ao conhecimento de técnicas e recursos de pesquisa; mas implica, acima de 
tudo, a consolidação de sua própria competência informacional para tornar concretas as situações em que a pesquisa escolar assuma o papel de substrato para a construção do conhecimento.

Cabe aqui retomar a análise contida no Relato 7, quando (PINHEIRO et al., 2009) refletem que o bibliotecário, dada a amplitude de sua atuação, deve intervir no processo de desenvolvimento de atividades que motivem a busca de conhecimento, não apenas no estímulo aos alunos, mas principalmente em relação aos professores, tendo como finalidade a possibilidade de estes se beneficiarem das possibilidades oferecidas pelas tecnologias disponíveis.

Deste modo, os relatos que compõem o corpus desta discussão permitem refletir sobre o objeto deste estudo, na medida em que identificam de maneira inequívoca a importância da pesquisa escolar como componente primordial no percurso do processo de construção do conhecimento.

Da mesma forma, a informação assume papel de destaque como ponto de partida e de chegada no processo de pesquisa, tendo como elemento mediador o bibliotecário.

Em suma, quando se abordam as relações existentes entre a pesquisa, o bibliotecário e o conhecimento, são reveladas inúmeras implicações, as quais, trazidas pelos relatos aqui compilados, devem ser consideradas como elementos basilares para a compreensão da importância de se implementar, no âmbito das bibliotecas escolares, ações concretas de estímulo à competência informacional.

\section{CONSIDERAÇÕES FINAIS}

A partir da discussão dos resultados da pesquisa, torna-se possível tecer algumas considerações sobre os mesmos, tendo em vista as contribuições trazidas para a ampliação da discussão sobre a importância da biblioteca escolar como espaço de fomento à pesquisa bem como sobre o papel do bibliotecário nesta tarefa.

Os artigos selecionados tratavam de experiências voltadas para os mais diferentes públicos, desde deficientes auditivos, alunos da Educação Infantil, do Ensino Fundamental, integrantes de cursos de graduação e de cursos de educação a distância (EAD), os quais traziam abordagens diferenciadas sobre a pesquisa como substrato da prática educativa. 
Tornou-se possível, pela leitura e análise destes relatos de experiência e de pesquisa, investigar como o bibliotecário pode contribuir para incentivar a prática da pesquisa na escola, transformando a biblioteca em espaço de conhecimento.

Nesta dimensão, verificou-se, sobretudo pelos relatos 7, 8, 9 e 12, que o bibliotecário assume importante função como elemento central na articulação entre a pesquisa, a biblioteca e a construção do conhecimento.

As diferentes etapas da presente pesquisa permitiram compreender como o bibliotecário pode contribuir e incentivar a pesquisa na escola, vislumbrando um extenso rol de possibilidades que podem ser adaptadas a cada realidade.

Deste modo, seja na organização de bibliotecas digitais, ou na proposição de atividades voltadas para os diferentes públicos das bibliotecas escolares ou até mesmo na construção de uma webquest, o bibliotecário possui uma importante função na formação da competência informacional necessária no atual momento da sociedade.

Quando se buscou analisar os relatos de pesquisa e relatos de experiência encontrados em revistas das áreas de Biblioteconomia e Ciência da Informação, foi possível identificar uma multiplicidade de temas que podem ser trazidos à tona no desenvolvimento do trabalho do bibliotecário, tendo em vista as inúmeras possibilidades de trabalho suscitadas pela pesquisa nas bibliotecas escolares.

Assim, ao discutir o papel do bibliotecário no incentivo à pesquisa na escola, não restam dúvidas de que este profissional representa um elemento vital na articulação entre a pesquisa e a aprendizagem.

Depois de analisar os artigos, tornou-se possível vislumbrar com maior clareza que o trabalho de pesquisa deve ser sugerido desde a Educação Infantil - conforme os resultados trazidos pelo Relato 11 -, para que a criança se familiarize com o processo e quando se the for sugerido nos anos seguintes, ela possa evoluir nesse caminho e dominar cada vez mais a metodologia de pesquisa.

Nos vários relatos de experiência e de pesquisa analisados durante o estudo, percebeu-se que só houve resultados positivos e uma condução satisfatória das atividades quando estavam envolvidos vários agentes, professor, aluno, bibliotecário, ou seja, a pesquisa é um constructo que somente é levado a termo como fruto de um esforço coletivo dos diferentes atores sociais que compõem a comunidade escolar. 


\section{REFERÊNCIAS}

ALMEIDA JÚNIOR, Oswaldo Francisco de. Pesquisa escolar: entre o modelo educacional e a liberdade da pesquisa. In: SILVA, Rovilson José da; BORTOLIN, Sueli (Org.). Fazeres cotidianos na Biblioteca Escolar. São Paulo: Polis, 2006. p. 97-103. (Coleção PalavraChave v. 17).

BEHR, Ariel et al. Especialização em bibliotecas escolares e acessibilidade: discutindo a gestão da biblioteca na modalidade EAD. Inf. Inf., Londrina, v. 16, n.1, jan./jun. 2011, p. 102-123. Disponível em:

<http://www.uel.br/revistas/uel/index.php/informacao/article/view/7831/8481>. Acesso em: 26 ago. 2012.

BICHERI, Ana Lúcia Antunes de Oliveira. A mediação do bibliotecário na pesquisa escolar face a crescente virtualização da informação. 2008. 197f. Dissertação (Mestrado em Ciência da Informação), Universidade Estadual Paulista - UNESP. Marília, 2008. Disponível em: <http://www.marilia.unesp.br/Home/Pos-

Graduacao/Cienciadalnformacao/Dissertacoes/bicheri_alao_me_mar.pdf $>$. Acesso em: 21 ago. 2013.

CAMPELLO, Bernardete Santos. Letramento informacional no Brasil: práticas educativas de bibliotecários em escolas de ensino básico. 2009. 209 f. Tese (Doutorado em Ciência da Informação) - Universidade Federal de Minas Gerais, Belo Horizonte, 2009. Disponível em:

<http://www.bibliotecadigital.ufmg.br/dspace/bitstream/handle/1843/ECID-

7UUPJY/tesebernadetesantoscampello.pdf?sequence=1 >. Acesso em: 30 jun. 2014 .

CAMPELLO, Bernardete Santos et al. Parâmetros para bibliotecas escolares brasileiras: fundamentos de sua elaboração I. Inf. \& Soc. Est., João Pessoa, v. 21, n. 2, maio/ago. 2011, p. 105-120. Disponível em:

<http://www.ies.ufpb.br/ojs/index.php/ies/article/view/10451/5965>. Acesso em: 26 set. 2012.

DEMO, Pedro. Educar pela pesquisa. 9 ed. rev. São Paulo: Autores Associados, 2011 (Coleção Educação Contemporânea).

. Introdução à metodologia da ciência. São Paulo: Atlas, 1983.

ESPÍRITO SANTO, Carmelita do; FREIRE, Isa Maria. "Quissamã somos nós!": construção participativa de hipertexto. Ci. Inf., Brasília, v. 33, n. 1, jan./abr. 2004, p. 155-168.

Disponível em: <http://www.scielo.br/scielo.php?pid=S0100-

$19652004000100019 \&$ script=sci_arttext>. Acesso em: 26 out. 2012.

FURTADO, Cássia. Educação e bibliotecas digitais. Revista Digital de Biblioteconomia e Ciência da Informação. Campinas, v. 8, n. 1, jul./dez. 2010, p.103-116. Disponível em: <http://www.sbu.unicamp.br/seer/ojs/index.php/rbci/article/view/433/294>. Acesso em 25 out. 2012. 
GARCEZ, Eliane Fioravante; CUNHA, Miriam Vieira da. O bibliotecário na escola de educação básica: depoimentos de profissionais de Santa Catarina. Inf. \& Soc. Est., João Pessoa, v. 21, n. 2, maio/ago. 2011, p. 121-131. Disponível em: <http://www.ies.ufpb.br/ojs/index.php/ies/article/view/9725/5985>. Acesso em: 25 out. 2012.

GUEDES, Clediane de Araújo; FARIAS, Gabriela Belmont de. Information literacy: uma análise nas bibliotecas escolares da rede privada em Natal / RN. Revista Digital de Biblioteconomia e Ciência da Informação, Campinas, v. 4, n. 2, jan./jun. 2007, p. 110133. Disponível em: <http://www.sbu.unicamp.br/seer/ojs/index.php/rbci/article/view/352/234>. Acesso em: 22 set. 2012.

KUHLTHAU, Carol Collier. Como usar a biblioteca na escola: um programa de atividades para ensino fundamental. (Traduzido e adaptado por Bernadete Santos Campello et al.). Belo Horizonte: Autêntica, 2002.

. O papel da biblioteca escolar no processo de aprendizagem. In: VIANNA, Márcia Milton; CAMPELLO, Bernadete; MOURA, Victor Hugo Vieira. Biblioteca escolar: espaço de ação pedagógica. Belo Horizonte: EB/UFMG, 1999, p. 9-14.

MORO, Eliane L. da Silva; ESTABEL, Lizandra Brasil. A Utilização das Tecnologias de Informação e de Comunicação na Pesquisa Escolar: um estudo de caso com os PNEEs com limitação visual. Em Questão, Porto Alegre, v. 10, n. 1, jan./jun. 2004, p. 185-199. Disponível em: <http://seer.ufrgs.br/index.php/EmQuestao/article/view/90/49>. Acesso em: 20 out. 2012.

PACHECO, Raquel. As transformações da escrita e seus suportes: do passado ao presente. Revista Digital de Biblioteconomia e Ciência da Informação. Campinas, v. 8, n. 2, jan./jun. 2011, p. 199-208. Disponível em:

<http://www.sbu.unicamp.br/seer/ojs/index.php/rbci/article/view/479/324>. Acesso em: 22 ago. 2012.

COSTA, Wilse Arena da; PINHEIRO, Mariza Inês da Silva; COSTA, Maria Neuma da Silva. O bibliotecário escolar incentivando a leitura através da webquest. Perspectivas em Ciências da Informação, Belo Horizonte, v. 14, n.1, jan/abr 2009, p. 37-54.

Disponível em: <http://www.scielo.br/pdf/pci/v14n1/v14n1a04.pdf>. Acesso em: 15 out. 2012.

PONTES JÚNIOR, João de; TÁLAMO, Maria de Fátima Gonçalves Moreira. Alfabetização digital: proposição de parâmetros metodológicos em competência informacional. Inf. \& Soc. Est., João Pessoa, v. 19, n. 2, maio/ago. 2009, p. 81-98. Disponível em: <http://www.ies.ufpb.br/ojs/index.php/ies/article/view/2990/3037>. Acesso em: 22 ago. 2012. 
SOUZA, Francisco das Chagas de. As possibilidades pedagógicas no ensino de metodologia da pesquisa científica em ciência da informação e os objetos deste campo científico: aproximações durkheinianas. Enc. Bibli: R. Eletr. Bibliotecon. Ci. Inf., Florianópolis, v. 8, n.16, jul./dez. 2003, p. 20-40. Disponível em: <https://periodicos.ufsc.br/index.php/eb/article/view/1518-2924.2003v8n16p20/5246>. Acesso em: 22 out. 2012.

SOUZA, Maria Aparecida Rodrigues de. Biblioteca do Colégio Estadual Manoel Vilaverde: um espaço além das quatro paredes. Revista Digital de Biblioteconomia e Ciência da Informação. Campinas, v. 3, n. 1, jul./dez. 2005, p. 152-164. Disponível em: <http://www.sbu.unicamp.br/seer/ojs/index.php/rbci/article/view/328/209>. Acesso em: 22 out. 2012.

\section{Title}

School research: course of action towards knowledge.

\section{Abstract}

Introduction: This study aims to present the importance of the school library, deepening the already initiated discussions on the subject. At the same time shows the relevance of the librarian's role in the pursuit of knowledge generation through the practice of research, reflection and discussion.

Objective: To analyze through literature of information science area, as the librarian can help and encourage research in school.

Methodology: Literature, a survey of scientific literature related to the topic on school research and the work of the librarian. Survey research reports and experience reports on actions undertaken with the aim of promoting the incentive to research.

Results: In several reports of experience and research analyzed during the research it was noted that the work only took effect or was conducted satisfactorily when it was involved various actors: teacher, student, librarian, etc.

Conclusions: When addressing the links between research, librarian and knowledge are revealed many implications, which, brought by the compiled reports, should be considered as basic elements for understanding the importance of implementing, within libraries school, concrete actions to stimulate the information literacy.

Keywords: Library. Research. Elementary Education. Librarian.

\section{Título}

Investigación escolar: curso de acción hacia el conocimiento

\section{Resumen}

Introducción: Este estudio tiene como objetivo presentar la importancia de la biblioteca de la escuela, la profundización de los debates ya iniciados en la materia. Al mismo tiempo, muestra la 
relevancia del papel del bibliotecario en la búsqueda de la generación de conocimiento a través de la práctica de la investigación, la reflexión y el debate.

Objetivo: Analizar la literatura a través de la información del área de ciencia, como el bibliotecario puede ayudar y fomentar la investigación en la escuela.

Metodología: Literatura, una encuesta de la literatura científica relacionada con el tema en la investigación de la escuela y el trabajo del bibliotecario. Informes de investigación de encuestas y relatos de experiencia sobre las acciones llevadas a cabo con el objetivo de promover el incentivo a la investigación.

Resultados: En varios informes de experiencia e investigación analizados durante la investigación se observó que el trabajo sólo surtió efecto o se llevó a cabo de manera satisfactoria cuando fue involucrado diversos actores: profesor, estudiante, bibliotecario, etc.

Conclusiones: Al abordar los vínculos entre la investigación, bibliotecario y el conocimiento se revelan muchas implicaciones, que, traída por los informes recopilados, deben ser considerados como elementos básicos para la comprensión de la importancia de la aplicación, dentro de las bibliotecas escuela, acciones concretas para estimular la alfabetización informacional.

Palabras clave: Biblioteca. Investigación. Educación básica. Bibliotecario.

Recebido em: 12.11 .2014

Aceito em: 22.12.2014 